\title{
Corrosion and Kinetic Study of Eucalyptus camaldulensis Seeds Extract Percolated with Methanol on Aluminium Coupons in $\mathrm{HCl}$
}

\section{Ishaq Yahaya Lawan ${ }^{1}$, Fatima Khalil Abdullah ${ }^{2}$, Sani Idris ${ }^{3}$, Shinggu D. Yamta ${ }^{4}$ and Abdurrahman Hudu ${ }^{5}$}

${ }^{1}$ Department of Chemistry, Nigerian Army University, Biu, Nigeria

${ }^{2}$ Department of Chemistry, Kano University of Science and Technology, Wudil, Nigeria

${ }^{3}$ Department of Chemistry, Kano University of Science and Technology, Wudil, Nigeria

${ }^{4}$ Department of Chemistry, Nigerian Army University, Biu, Nigeria

${ }^{5}$ Department of Chemistry, Nigerian Army University, Kano, Nigeria

\begin{abstract}
This research discusses a detail optimization of Eucalyptus camaldulensis seeds extract as corrosion inhibitor for aluminum coupons in $\mathrm{HCl}$ using weight loss measurement and kinetic study. The result shows that the maximum inhibitor efficiency was obtained at a concentration of $2.0(\% \mathrm{~W} / \mathrm{V})$. However the highest inhibitor efficiency of $85 \%$ was obtained at $50^{\circ} \mathrm{C}$ and the least inhibitor efficiency of $29 \%$ was obtained at $30^{\circ} \mathrm{C}$. Thermodynamic consideration revealed that adsorption of inhibitor of aluminum surface was exothermic and consistent with chemical adsorption mechanism.
\end{abstract}

\section{Introduction}

The significant of corrosion protection of carbon steel in acidic solutions has become necessary due to its propensity to be attacked in acidic media when deployed in services like acid electrochemical systems, oil recovery and also the petrochemical industry. The protection of carbon steel against corrosion in acidic environment can be achieved in various ways using corrosion inhibitors [1-3]. Several research have been carried out on

Received: September 30, 2019; Revised: December 18, 2019; Accepted: December 26, 2019

Keywords and phrases: corrosion, inhibitor, Eucalyptus camaldulensis, coupon, kinetic study.

Copyright () 2020 Ishaq Yahaya Lawan et al. This is an open access article distributed under the Creative Commons Attribution License, which permits unrestricted use, distribution, and reproduction in any medium, provided the original work is properly cited. 
the use of eco-friendly inhibitors to contain corrosion of carbon steel, aluminum and many other metals in both acid and alkaline solutions [4-7]. Corrosion inhibitor are commonly added in small quantity to pickling acids, acid stimulation fluids, cooling water, oil and gas production streams, either continuously or intermittently to control attacks. This inhibitor generally control corrosion by forming various types of films either by adsorption or the formation of bulky precipitates, and/or the formation of a passive layer on the metal surface that modify it's corrosively [9-10]. The mechanism of most corrosion inhibitor on metal oxidation can be explained inhibitor on metal oxidation can be explained on the basis of molecular adsorption, which involves forming a thin, invisible film that coat the metal thereby protecting it from attack or a combination of adsorption films and corrosion products form a passive layer on the metal surface [11]. In acidic solutions, corrosion inhibitor subsist either as neutral molecules which adsorb on the metal/acid solution interface through electrostatic attraction between charged molecules and unshared $\pi$ electrons in the inhibitor molecules and charged metal surface [12]. Apart from sea water, hydrochloric acid remains the main source of the aggressive chloride ions in aqueous solutions and occurrences of carbon steel corrosion in environments containing chloride ions are known [13]. Several reports claimed the use of green inhibitor as cheap, effective, renewable and non-toxic for metal corrosive [14-20]. The effectiveness of these bio-extracts as metal corrosion inhibitor mainly depend on its phytocompound function groups having; steric effect, $\pi$-orbital character of donating electrons via adsorption at active sites and electronic density of donor atoms among other variable.

Inhibitors are substances which reduce metallic corrosion by changing the structure of the double layer, reducing the effective electrode area, decreasing metal reactivity (Abdallah et al. [18]).

Inhibitors are also substances which when added to the environment, usually in small quantity effectively reduce corrosion (Eddy [19]). Inhibitors are classified depending on the number of orientation.

Based on their chemical nature as organic and inorganic and based on the nature of their polarizing action into anodic and cathodic inhibitor.

\section{Aluminum steel}

Aluminum is a chemical element in the boron group with symbol $\mathrm{Al}$ and atomic number 13. It is a silvery-white, soft, non-magnetic, ductile metal. Aluminum is the third 
most abundant element (after oxygen and silicon), and the most abundant metal in the earth's crust, it makes up about $8 \%$ by mass of the earth crust, though it is less common in the mantle below. Aluminum metal is so chemically reactive that native specimen and rare and limited to extreme reducing environments. Instead, it is found combined in over 270 different minerals (Saraswathi et al. [22]). The cheap ore is bauxite.

Aluminum is remarkable for the metal's low density and for its ability to resist corrosion due to the phenomenon of passivation (Frank [14])

Corrosion resistance can be excellent due to a thin surface layer of aluminum oxide that forms when the metal is exposed to air, effectively preventing further oxidation (Vargel [13]). The strongest aluminum alloys are less corrosion resistance due o galvanic reaction with alloyed copper. (Polmear [10]) this corrosion resistance is also often greatly reduced by aqueous salts, particularly in the presence of dissimilar metals. In high acidic solutions, aluminum reacts with water to form hydrogen, and highly alkaline one to form aluminates-protective passivation under these condition is negligible-also, chlorides such as common sodium chloride are well known sources of corrosion of aluminum (Beal [15]).

\section{Eucalyptus camaldulensis}

Eucalyptus camaldulensis, the river red gum is a tree of the genus eucalyptus. It is one of around 800 in the genus. It is a plantation species in many parts of the world, but is native to Australia, where it has the most widespread natural distribution of Eucalyptus in Australia (Colloff [9]); especially beside inland water courses. Oddly, it is named for a private estate garden near camaldoli monastery near Naples, from where first specimen came to be described. Material from this tree was used by Frederick Delinhardf chief gardener at the botanic gardens in Naples to describe this species in 1832 (Slee et al. [8]).

\section{Eucalyptus camaldulensis seed}

The seeds are yellow or yellowish brown, cuboids and smooth (Walsh and Entwisle [23]) and can be difficult to distinguish from chaft (Bonney [11]). They have long ripening period, usually maturing during the summer months, about one year after flowering (Ralph [21]). Valves on maturing fruit will turn from green to brownish-red when ripe (Bonney [11]). Temperature and seasonal condition will detect when seed is ready to pick and seed release can occur quickly onces matured (Bonney [11]). 
In this present work, corrosion study was made using Alluminium coupons immersed in aerated acid solutions with Eucalyptus camaldulensis seed.

\section{Materials/reagents}

Volumetric flasks (250ml), Measuring cylinder (100ml), Glass Beakers, Thermometers $\left(0-360^{\circ} \mathrm{C}\right)$, Water baths, Reagent bottles, Filter paper, Sieve, Funnel, Electric oven, Stop watch, Aluminium caupons, Hydrochloric acid $(\mathrm{HCl})$, Absolute Methanol $\left(\mathrm{CH}_{3} \mathrm{OH}\right)$, Potassium hydroxide $(\mathrm{KOH})$, Acetone , Hook.

\section{Preparation of inhibitor}

The Eucalyptus camaldulensis seeds were spread out in a laboratory for two weeks for dried and were transferred to an electric oven at $100^{\circ} \mathrm{C}$ for an hour in other to be properly dried, and then ground to powder. The powdered seeds were added to Methanol and soaked in a beaker at room temperature for 48 hours and the dark brown sample was filtered and the resulting filtrate was evaporated by using rotator evaporation for some hours in other to leave the sample free from methanol, the extracts obtained was used to prepared various concentration of inhibitor.

\section{Preparation of standard solution of hydrochloric acid}

A standard solution is a solution of known concentration. The amount of a solution is measure in various ways. The amount of substance dissolve per unit volume of the solution has a unit of mol dm $\mathrm{dm}^{-3}$ and is called molarity. Also, the mass concentration is the mass of solute per unit volume of solution. It has a unit of $\mathrm{g} \mathrm{dm}^{-3}$ or $\mathrm{g} \mathrm{cm}^{-3}$.

Several concentration of hydrochloric acid could be effectively prepared, by dissolving the suitable weight in $500 \mathrm{ml}$ of distilled water in $500 \mathrm{~cm}^{3}$ volumetric flasks.

From commercial acid whose bottle was labeled as follows:

Percentage purity $=36.5 \%$

Specific gravity $=1.2 \mathrm{~g} \mathrm{~cm}^{-1}$

Molar mass $=36.46 \mathrm{~g} \mathrm{~cm}^{-1}$. 
Using the relation to calculation the concentration in mol $\mathrm{dm}^{-3}$

$$
\begin{aligned}
\text { Concentration in mol dm } & =\frac{\text { percentage purity } \times \text { specific gravity } \times 1000}{\text { molar mass }} \\
& =\frac{36.5 \times 1.2 \times 1000}{36.46} \\
& =12.01 \mathrm{~mol} \mathrm{dm}^{-3} .
\end{aligned}
$$

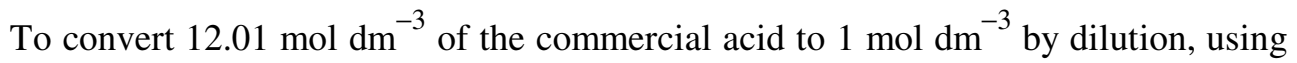
the relation

$$
\mathrm{C}_{1} \mathrm{~V}_{1}=\mathrm{C}_{2} \mathrm{~V}_{2}
$$

where

$\mathrm{C}_{1}=$ concentration of acid in $12.01 \mathrm{~mol} \mathrm{dm}^{-3}$

$\mathrm{C}_{2}=$ concentration of dilute acid in mol dm ${ }^{-3}$

$\mathrm{V}_{1}=$ initial volume of the acid in $\mathrm{cm}^{3}$

$V_{2}=$ first volume of the dilute acid in $250 \mathrm{~cm}^{3}$.

Substituting

$12.01 \mathrm{~mol} \mathrm{dm}^{-3} \times \mathrm{V}_{1}=1 \mathrm{~mol} \mathrm{dm}{ }^{-3} \times 250 \mathrm{~cm}^{3}$

$\mathrm{V}_{1}=250 \mathrm{~cm}^{3} \times 1 \mathrm{~mol} \mathrm{dm}^{-3} / 12.01 \mathrm{~mol} \mathrm{dm}^{-3}$

$\mathrm{V}_{2}=20.81$ or $21 \mathrm{~cm}^{3}$ (approximation).

$21 \mathrm{~cm}^{3}$ of a commercial acid was taken into a beaker which; contain about $100 \mathrm{~cm}^{3}$ of distilled water and the solution was stared. The solution was transferred into $250 \mathrm{~cm}^{3}$ volumetric flask, the beaker was rinse with more distilled water and it was pour into the solution in volumetric flask until it reaches the meniscus level of the flask. That was how to prepare to $1 \mathrm{~mol} \mathrm{dm}{ }^{-3} \mathrm{HCl}$. The same procedure was repeated in the preparation of 2 , 3 , and $4 \mathrm{~mol} \mathrm{dm}^{-3}$ solutions. 


\section{Preparation of coupons}

The aluminum coupons were cut into $3 / 5 \mathrm{~cm}$ coupons. The coupons were cleaned and decreased in absolute methanol, dried in an electric oven and were stored in a desiccators prior to use.

\section{Preparation of hydrochloric acid/inhibitor}

Several concentrations of hydrochloric acid and inhibitor were prepared by dissolving adequate amount of inhibitor in $50 \mathrm{ml}$ of $3 \mathrm{~mol} \mathrm{dm}^{-3}$ hydrochloric acid.

For example,

To prepared $0.5(\% \mathrm{~W} / \mathrm{V})$ of the inhibitor in $3 \mathrm{~mol} \mathrm{dm}^{-3} \mathrm{HCl}$

$(\% \mathrm{~W} / \mathrm{V})=[$ weight of solute $/$ volume of solution $] \times 100$

$$
=(0.25 / 50) \times 100
$$

$=0.5(\% \mathrm{~W} / \mathrm{V})$.

The same procedure was used for $1.0(\% \mathrm{~W} / \mathrm{V}), 1.5(\% \mathrm{~W} / \mathrm{V})$, and $2.0(\% \mathrm{~W} / \mathrm{V})$ respectively.

\section{Experimental procedures}

The first was carried out by introducing 1,2,3, and $4 \mathrm{~mol} \mathrm{dm}^{-3}$ into four (4) sets of beaker respectively. The coupons were immersed in each of the test solution containing $\mathrm{HCl}$. Each test was carried out at different temperature ranging from $30-50^{\circ} \mathrm{C}$. The coupons were withdrawn from the acid after five hours and immersed in $\mathrm{KOH}$ solution to quench the reaction, scrub with bristle brush in distilled water and dried in acetone and then reweighed.

The second test, involved the introduction of $0.25 \mathrm{~g}, 0.5 \mathrm{~g}, 0.75 \mathrm{~g}$ and $1.0 \mathrm{~g}$ of extracts into $50 \mathrm{ml}$ of $3 \mathrm{M}$ in $400 \mathrm{~cm}^{3}$ beaker at 30,40 and $50^{\circ} \mathrm{C}$, respectively. The previously weighed coupons were introduce into each five set of beaker each coupons was withdrawn from their respective solution after five hours, washed as before and weighed.

At the end of the experiment, the weight loss, corrosion rate, inhibitor efficiency, degree of surface coverage, free energy, activation energy, half-life and heat of adsorption were calculated. 
The weight loss was calculated by finding the difference between the initial weight of the coupons and the final weight after 5 hours. Using the relationship (Okafor et al. [26])

$$
\mathrm{W}=\mathrm{W}_{\mathrm{i}}-\mathrm{W}_{\mathrm{f}},
$$

where

$$
\begin{aligned}
& \mathrm{W}=\text { weight loss } \\
& \mathrm{W}_{\mathrm{i}}=\text { initial weight } \\
& \mathrm{W}_{\mathrm{f}}=\text { final weight. }
\end{aligned}
$$

The corrosion rate was determined from standard expression for measurement of corrosion rate in millimeters per year (MMPY).

$$
\mathrm{MPY}=\frac{87.6 \mathrm{~W}}{\mathrm{DAT}},
$$

where

$$
\begin{aligned}
& \mathrm{W}=\text { weight loss }(\mathrm{mg}) \\
& \mathrm{D}=\text { density of material used }\left(\mathrm{g} \mathrm{cm}^{-3}\right) \\
& \mathrm{T}=\text { time of exposure (hour) } \\
& \mathrm{A}=\text { total surface Area }\left(\mathrm{cm}^{2}\right) .
\end{aligned}
$$

Inhibitor efficiency (IE) \% was computed using the relationship (Abiola and James [27]).

$$
\text { Inhibitor efficiency (IE) } \%=1-\frac{\mathrm{W}_{1}}{\mathrm{~W}_{2}} \times 100 \text {, }
$$

where

$$
\begin{aligned}
& \mathrm{W}_{1}=\text { corrosion rate with inhibitor } \\
& \mathrm{W}_{2}=\text { corrosion rate without inhibitor. }
\end{aligned}
$$

Degree of total surface coverage $(\theta)$ was calculated using the relationship (Abiola and James [27]).

$$
\text { Degree of total coverage }=1-\frac{\mathrm{W}_{1}}{\mathrm{~W}_{2}} .
$$




\section{Kinetic study}

The activation energy (EA) of the corrosion rate was calculated using the Arrhenius equation given by (Abiola and James [27])

$$
\log \frac{R_{1}}{R_{2}}=\frac{E a}{2.303 R}\left(\frac{1}{T_{1}}-\frac{1}{T_{2}}\right)
$$

where $R_{1}$ and $R_{2}$ are the corrosion rates at any given two different temperatures $T_{1}$ and $T_{2}$.

The free energy of adsorption $(\Delta \mathrm{G})$ was determined, using the given relationships (Abiola and James [27]).

$$
\Delta \mathrm{G}(\mathrm{ads})=-\mathrm{RT} \ln (55.5 \mathrm{k})
$$

where

$$
\begin{aligned}
K & =\frac{\theta}{c(1-\theta)} \\
K & =\text { equilibrium constant, } \\
\theta & =\text { degree of surface coverage } \\
C & =\text { concentration of the inhibitor. }
\end{aligned}
$$

Also the heat of adsorption (HADS) of the inhibitor was calculated using the relationship (Chetouani et al. [1])

$$
\Delta \text { Hads }=2.303 R\left[\left(\log \frac{\theta_{2}}{1-\theta_{2}}\right)-\left(\log \frac{\theta_{1}}{1-\theta_{1}}\right)\right] \times T_{1} T_{2} / T_{2}-T_{1}\left(\mathrm{jmol}^{-1}\right),
$$

where $\theta_{1}$ and $\theta_{2}$ are degree of surface coverage at any two temperature $T_{1}$ and $T_{2}$. 


\section{Result and Discussion}

Table 1. Corrosion rate with concentration of $\mathrm{HCl}$ without inhibitor at $30^{\circ} \mathrm{C}, 40^{\circ} \mathrm{C}$ and $50^{\circ} \mathrm{C}$.

\begin{tabular}{|c|c|c|c|}
\hline \multirow{2}{*}{$\begin{array}{c}\text { Concentration of } \mathrm{HCl} \\
\left(\mathrm{mol} \mathrm{dm}^{-3}\right)\end{array}$} & \multicolumn{3}{|c|}{ Corrosion rate (mils/year) } \\
\cline { 2 - 4 } & $30^{\circ} \mathrm{C}$ & $40^{\circ} \mathrm{C}$ & $50^{\circ} \mathrm{C}$ \\
\hline 1 & 1081.48 & 1158.73 & 1313.23 \\
\hline 2 & 1313.23 & 1467.72 & 1544.97 \\
\hline 3 & 1467.72 & 1619.37 & 2085.71 \\
\hline 4 & 1699.47 & 1931.22 & 2471.96 \\
\hline
\end{tabular}

Table 2. Corrosion rate with concentration of inhibitor at $30,40,50^{\circ} \mathrm{C}$.

\begin{tabular}{|c|c|c|c|}
\hline \multirow{2}{*}{$\begin{array}{c}\text { Inhibitor concentration } \\
(\% \mathrm{~W} / \mathrm{V})\end{array}$} & \multicolumn{3}{|c|}{ Corrosion rate (mils/year) } \\
\cline { 2 - 4 } & $30^{\circ} \mathrm{C}$ & $40^{\circ} \mathrm{C}$ & $50^{\circ} \mathrm{C}$ \\
\hline 0.5 & 1042.86 & 919.26 & 463.49 \\
\hline 1.0 & 934.71 & 896.08 & 324.44 \\
\hline 1.5 & 919.26 & 845.01 & 293.54 \\
\hline 2 & 903.81 & 795.66 & 262.65 \\
\hline
\end{tabular}

Table 3. Inhibitor efficiency with inhibitor concentration at $30,40,50^{\circ} \mathrm{C}$

\begin{tabular}{|c|c|c|c|}
\hline \multirow{2}{*}{$\begin{array}{c}\text { Inhibitor concentration } \\
(\% \mathrm{~W} / \mathrm{V})\end{array}$} & \multicolumn{3}{|c|}{ Inhibitor efficiency (\%) } \\
\cline { 2 - 4 } & $30^{\circ} \mathrm{C}$ & $40^{\circ} \mathrm{C}$ & $50^{\circ} \mathrm{C}$ \\
\hline 0.5 & 29 & 21 & 65 \\
\hline 1.0 & 36 & 42 & 79 \\
\hline 1.5 & 37 & 50 & 91 \\
\hline 2.0 & 38 & 67 & 94 \\
\hline
\end{tabular}


Table 4. Free energy $\left(\mathrm{J} \mathrm{mol}^{-1}\right)$ with inhibitor concentration at 30,40 and $50^{\circ} \mathrm{C}$.

\begin{tabular}{|c|c|c|c|}
\hline \multirow{2}{*}{$\begin{array}{c}\text { Inhibitor concentration } \\
(\% \mathrm{~W} / \mathrm{V})\end{array}$} & \multicolumn{3}{|c|}{ Free energy $\left(\mathrm{J} \mathrm{mol}^{-1}\right)$} \\
\cline { 2 - 4 } & $30^{\circ} \mathrm{C}$ & $40^{\circ} \mathrm{C}$ & $50^{\circ} \mathrm{C}$ \\
\hline 0.5 & -9608.61 & -11522.35 & -16046.31 \\
\hline 1.0 & -8668.62 & -9929.70 & -15239.09 \\
\hline 1.5 & -7755.87 & -9188.55 & -14572.00 \\
\hline 2.0 & -7138.63 & -8752.31 & -14029.50 \\
\hline
\end{tabular}

Table 5. Degree of surface coverage $(\theta)$ with inhibitor concentration.

\begin{tabular}{|c|c|c|c|}
\hline \multirow{2}{*}{$\begin{array}{c}\text { Inhibitor concentration } \\
(\% \mathrm{~W} / \mathrm{V})\end{array}$} & \multicolumn{3}{|c|}{ Degree of surface coverage $(\theta)$} \\
\cline { 2 - 4 } & $30^{\circ} \mathrm{C}$ & $40^{\circ} \mathrm{C}$ & $50^{\circ} \mathrm{C}$ \\
\hline 0.5 & 0.29 & 0.43 & 0.78 \\
\hline 1 & 0.36 & 0.45 & 0.84 \\
\hline 1.5 & 0.37 & 0.48 & 0.86 \\
\hline 2 & 0.38 & 0.51 & 0.87 \\
\hline
\end{tabular}

Table 6. Heat of adsorption (Hads) for Eucalyptus camaldulensis seeds.

\begin{tabular}{|c|c|}
\hline $\begin{array}{c}\text { Concentration of Eucalyptus } \\
\text { camaldulensis seeds }(\% \mathrm{~W} / \mathrm{V})\end{array}$ & Heat of adsorption $(\mathrm{Hads})\left(\mathrm{J} \mathrm{mol}^{-1}\right)$ \\
\cline { 2 - 2 } & At 30 and $40^{\circ} \mathrm{C}$ \\
\hline 0.5 & -8898.11 \\
\hline 1.0 & -4685.13 \\
\hline 1.5 & -8715.70 \\
\hline 2.0 & -11512.98 \\
\hline
\end{tabular}

Table 7. Activation energy (-Ea) with concentration of inhibitor

\begin{tabular}{|l|l|}
\hline $\begin{array}{l}\text { Concentration of Eucalyptus camaldulensis } \\
\text { seeds }\end{array}$ & $\begin{array}{l}\text { Activation energy (Ea) }\left(\mathrm{J} \mathrm{mol}^{-1}\right) \text { at } \\
40^{\circ} \mathrm{C} \text { and } 50^{\circ} \mathrm{C}\end{array}$ \\
\hline 0.5 & $57,577.94$ \\
\hline 1.0 & $85,421.23$ \\
\hline 1.5 & $88,603.64$ \\
\hline 2.0 & $93,192.12$ \\
\hline
\end{tabular}




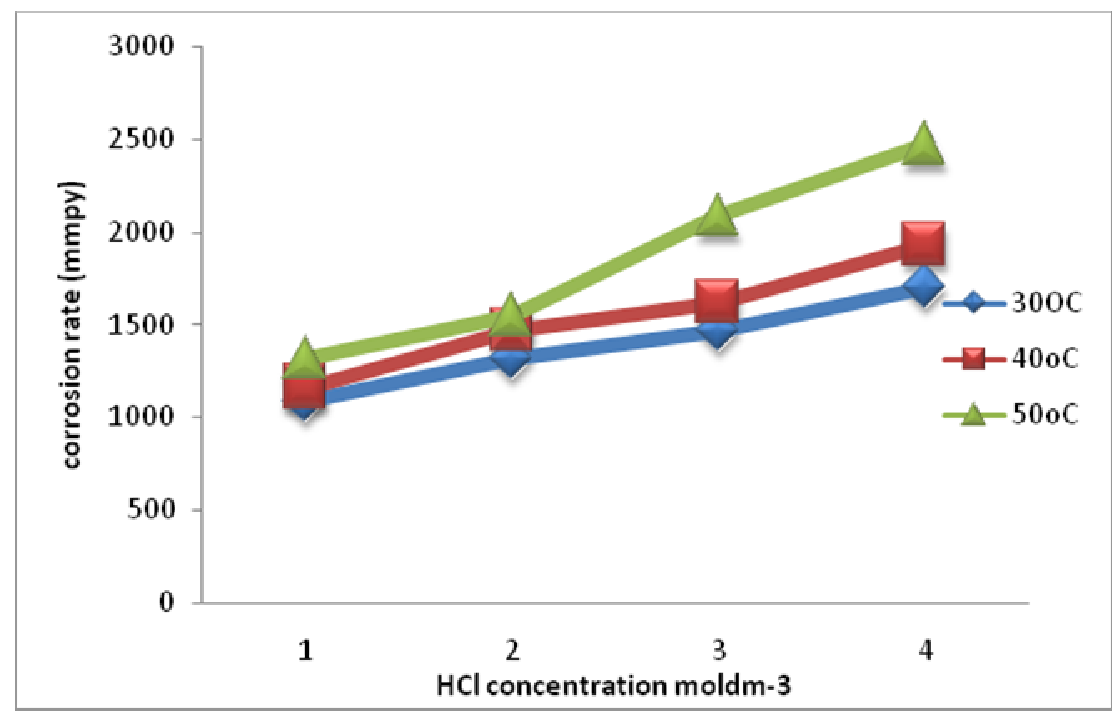

Figure 1. Variation of corrosion rate with concentration of $\mathrm{HCl} 30^{\circ} \mathrm{C}, 40^{\circ} \mathrm{C}$ and $50^{\circ} \mathrm{C}$.

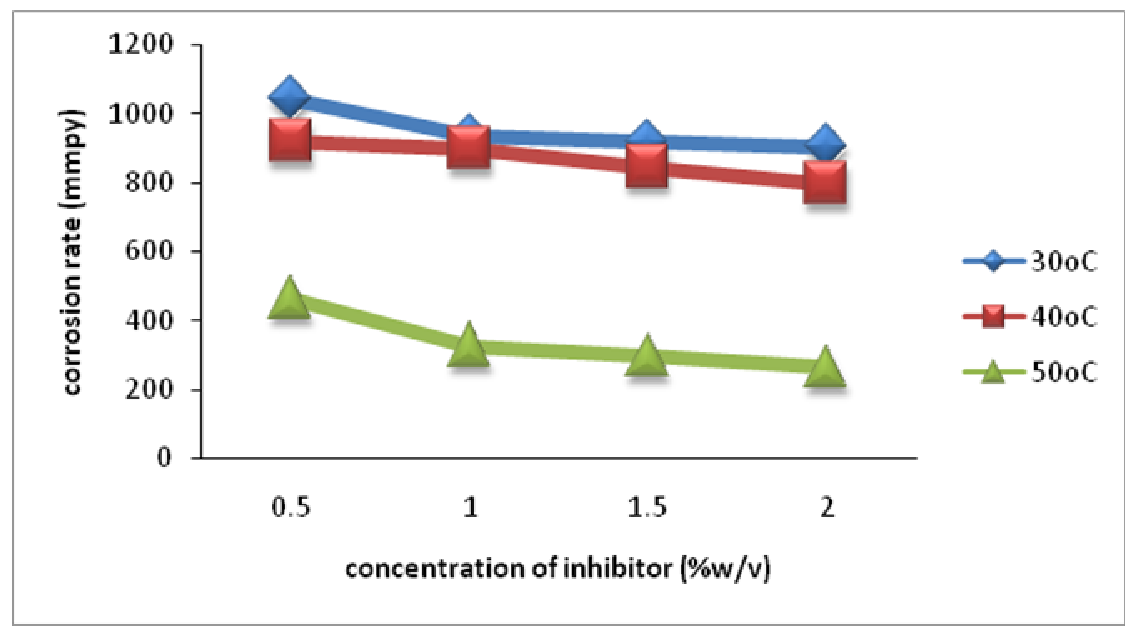

Figure 2. Variation of corrosion with of inhibitor at $30^{\circ} \mathrm{C}, 40^{\circ} \mathrm{C}$ and $50^{\circ} \mathrm{C}$. 


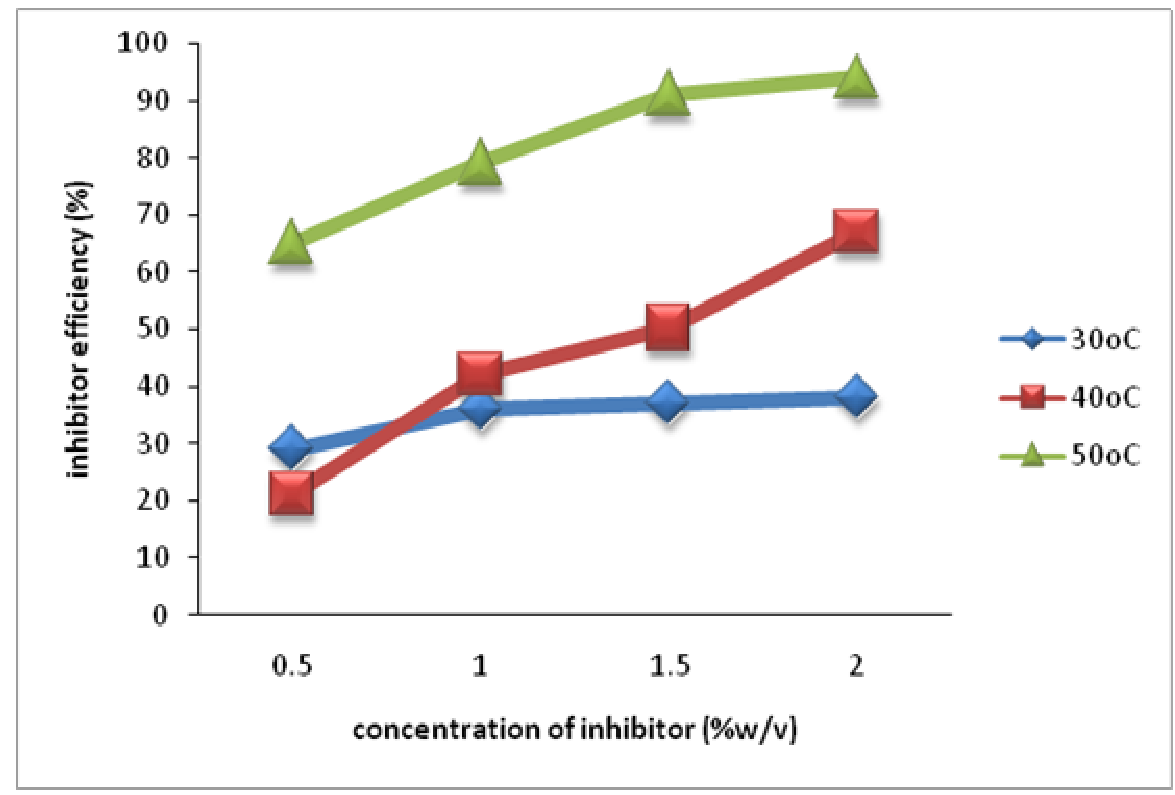

Figure 3. Variation of inhibitor efficiency with inhibition concentration at $30^{\circ} \mathrm{C}, 40^{\circ} \mathrm{C}$ and $50^{\circ} \mathrm{C}$.

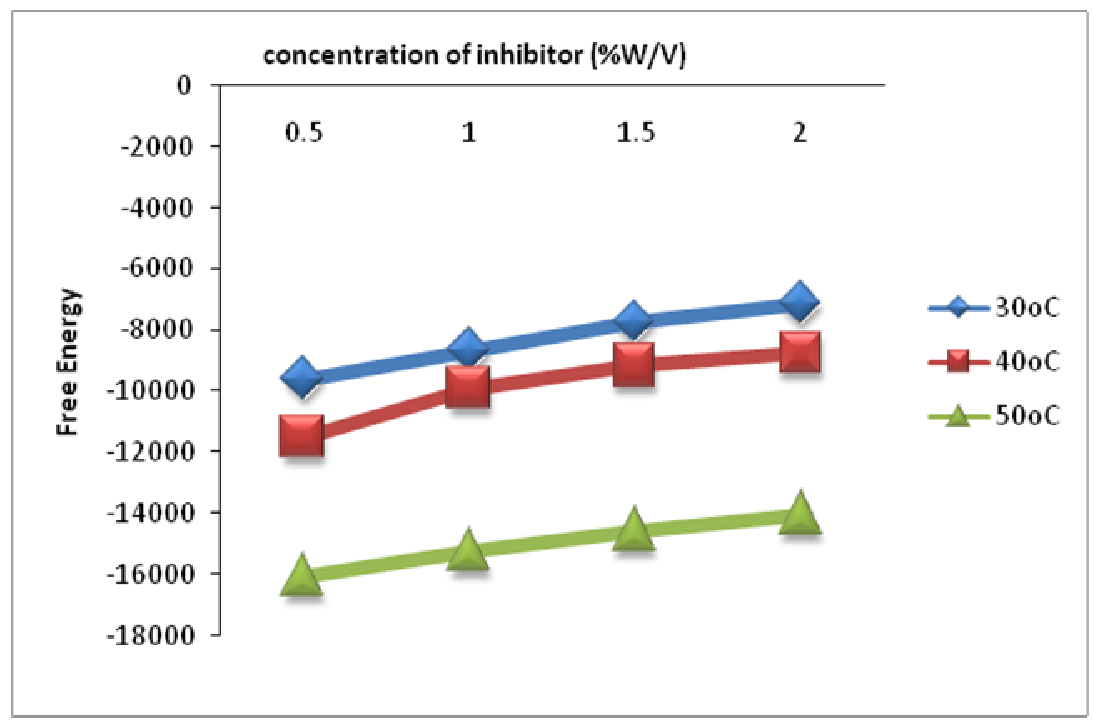

Figure 4. Variation of free energy with concentration of inhibitor at $30^{\circ} \mathrm{C}, 40^{\circ} \mathrm{C}$ and $50^{\circ} \mathrm{C}$. 


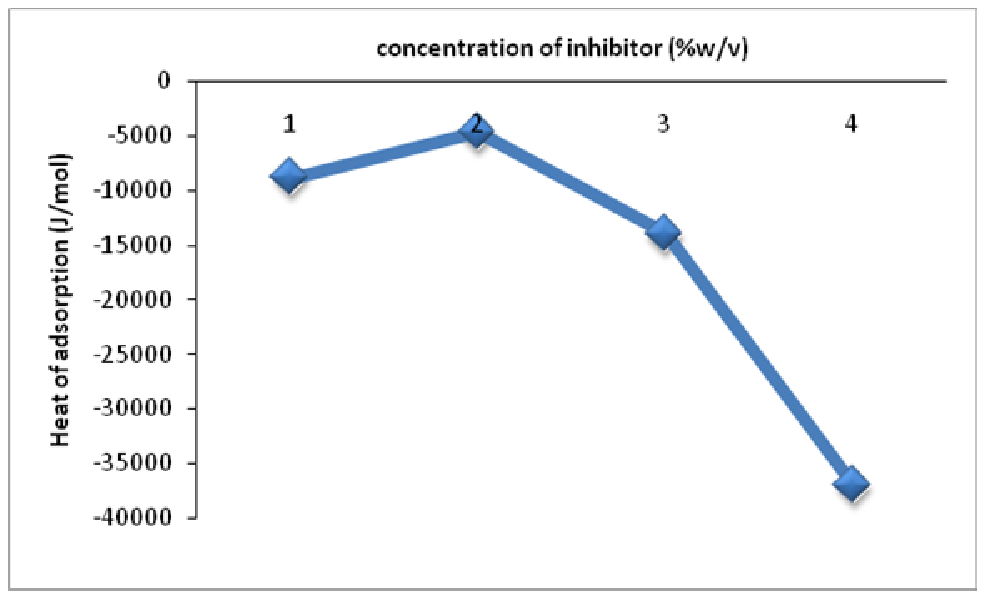

Figure 5. Variation of heat adsorption ( Had) $\left(\mathrm{J} \mathrm{mol}^{-1}\right)$ with of inhibitor at 30 and $40^{\circ} \mathrm{C}$.

\section{Discussion}

The successful of Eucalyptus camaldulensis seeds extract as an inhibitor of the corrosion of aluminum coupons in acidic medium was carefully examined using weight loss measurement. Also, adequate observation of coupons in the absence and presence of inhibitor after 5 hours of exposure shows changes in colour of coupons.

Figure 1 shows values of corrosion rate with concentration of $\mathrm{HCl}$ in the absent of inhibitor at $30^{\circ} \mathrm{C}, 40^{\circ} \mathrm{C}$ and $50^{\circ} \mathrm{C}$, the trend shows an increase in corrosion rate with variation in concentration from 1.0 to $4.0\left(\mathrm{~mol} \mathrm{dm}{ }^{-3}\right)$ at $30^{\circ} \mathrm{C}, 40^{\circ} \mathrm{C}$ and $50^{\circ} \mathrm{C}$. The highest rate of corrosion was observed at $50^{\circ} \mathrm{C}$ in concentration of $4 \mathrm{~mol} \mathrm{dm}{ }^{-3}$, while the least corrosion rate was observed in $1.0 \mathrm{~mol} \mathrm{dm}^{-3}$ concentration. This means the higher the concentration of $\mathrm{HCl}$ the higher the corrosion rate also the lower the $\mathrm{HCl}$ concentration the lower the corrosion rate.

Figure 2 shows that the corrosion rate for the corrosion of aluminum coupons at 0.5 to 2.0 in $3 \mathrm{~mol} \mathrm{dm}^{-3} \mathrm{HCl}$ in the presence of aluminum coupons at temperature $30^{\circ} \mathrm{C}$, $40^{\circ} \mathrm{C}$ and $50^{\circ} \mathrm{C}$. It may be observed from the data in Figure 2 that an increased in concentration of the inhibitor generally retard the corrosion rate of aluminum coupons in the acid solution. This is also seen and supported from the decreasing change in mass loss taking place at a particular acid concentration corresponding with an increase in inhibitor concentration. 
Figure 3 shows that the inhibitor efficiency of Eucalyptus camaldulensis extract varies with its concentration. Optimum value of the inhibitor efficiency was obtained at a concentration of $2.0(\% \mathrm{w} / \mathrm{v})$. The highest inhibitor efficiency of $85 \%$ was obtained at $50^{\circ} \mathrm{C}$. While the least value were obtain at an extract concentration of $0.5(\% \mathrm{w} / \mathrm{v})$, with inhibitor efficiency of $29 \%$ which was obtain at $30^{\circ} \mathrm{C}$. The difference between the trends for inhibitor efficiency of eucalyptus camaldulensis extract obtain at $30^{\circ} \mathrm{C}, 40^{\circ} \mathrm{C}$ and $50^{\circ} \mathrm{C}$ at the acid concentration over the range of Eucalyptus camaldulensis concentration presently studied strongly suggest that the mechanism of adsorption of the inhibitor on the aluminum coupon surface is predominantly by chemical adsorption.

Figure 4 shows the variation of free energy with inhibitor concentration at $30^{\circ} \mathrm{C}$, $40^{\circ} \mathrm{C}$ and $50^{\circ} \mathrm{C}$. The graph shows that the highest free energy was obtain in inhibitor concentration of $2.0(\% \mathrm{w} / \mathrm{v})$ at $30^{\circ} \mathrm{C}$ while the least was observe at $0.5(\% \mathrm{w} / \mathrm{v})$ at $50^{\circ} \mathrm{C}$. The negative value of free energy of adsorption suggests a strong interaction of the inhibitor molecules on the surface of the aluminum coupons (Monticelli et al. [16]).

In Figure 5, the graph shows that the value of heat adsorption were negative at all Eucalyptus camaldulensis extract concentration studied and ranged from -36990.71 to $-8898.11(\mathrm{~J} / \mathrm{mol})$. Indicate that the adsorption of the extract on aluminum coupon surface is exothermic. The negative value shows that the adsorption and hence the inhibitor efficiency decreases with rise in temperature.

\section{References}

[1] A. Chetouani, B. Hammouti and M. Benkaddour, Corrosion inhibition of iron in hydrochloric acid solution by jojoba oil, Pigment \& Resin Technology 33 (2004), 26-31. https://doi.org/10.1108/03699420410512077

[2] M. G. Sethuraman and P. Bothi Raja, Corrosion inhibition of mild steel by Datura metel in acidic medium, Pigment \& Resin Technology 34 (2005), 327-331. https://doi.org/10.1108/03699420510630345

[3] Z. Ait Chikh, D. Chebabe, A. Dermaj, N. Hajjaji, A. Srhiri, M. F. Montemor, M. G. S. Ferreira and A. C. Bastos, Electrochemical and analytical study of corrosion inhibition on carbon steel in $\mathrm{HCl}$ medium by 1,12-bis(1,2,4-triazole) dodecane, Corrosion Science 47 (2005), 447-459. https://doi.org/10.1016/j.corsci.2004.05.028

[4] Lin Niu, Hu Zhang, Fenghua Wei, Suxiang Wu, Xiaoli Cao and Pengpeng Liu, Corrosion inhibition of iron in acidic solutions by alkyl quaternary ammonium halides: 
Correlation between inhibition efficiency and molecular structure, Applied Surface Science 252(5) (2005), 1634-1642. https://doi.org/10.1016/j.apsusc.2005.02.134

[5] Y. El-Etre, M. Abdallah and Z. E. El-Tantawy, Corrosion inhibition of some metals using lawsonia extract, Corrosion Science 47(2) (2005), 385-395.

https://doi.org/10.1016/j.corsci.2004.06.006

[6] P. Bothi Raja and M. G. Sethuraman, Strychnos nux-vomica an eco-friendly corrosion inhibitor for mild steel in $1 \mathrm{M}$ sulfuric acid medium, Materials and Corrosion 60 (2009), 22-28. https://doi.org/10.1002/maco.200805027

[7] A. M. Abdel-Gaber, B. A. Abd-El-Nabey and M. Saadawy, The role of acid anion on the inhibition of the acidic corrosion of steel by lupine extract, Corrosion Science 51 (2009), 1038-1042. https://doi.org/10.1016/j.corsci.2009.03.003

[8] Andrew Slee, M. I. H. Brooker, S. M. Duffy and J. G. West, "River Red Gum" Eucalyptus camaldulensis var. obtuse, Centre for Plant Biodiversity Research, 2006. Retrieved: 2012-06-16.

[9] Matthew Colloff, Flooded Forest and Desert Creek, CSIRO Publishing, 2014. https://doi.org/10.1071/9780643109209

[10] I. J. Polmear, Light Alloys: Metallurgy of the Light Metals, 3rd ed., London: Arnold, 1995.

[11] N. Bonney, What Seed is That?, 2nd ed., Neville Bonney, Tantanoola, SA, 2003.

[12] M. H. Brooker, A. V. Slee, J. R. Connors and S. M. Duffy, EUCLID Eucalypts of Southern Australia, CD-ROM, CSIRO Publishing, Collingwood, VIC, 2002

[13] C. Vargel, Corrosion of Aluminum, Elsevier, London, 2004. https://doi.org/10.1016/B978-008044495-6/50012-4

[14] W. B. Frank et al., Alumium, in: Ullmann's Encyclopedia of Industrial Chemistry, Wiley-VCH, 2009. https://doi.org/10.1002/14356007.a01_459.pub2

[15] R. E. Beal, Corrosion and testing of engine coolants engine coolant testing fourth volume, ASTM STP 1335, R.E Beal, Ed-American society for testing and material 1999. PP. 89-112. https://doi.org/10.1520/STP1335-EB

[16] C. Monticelli, F. Zucchi, G. Brunoro and G. Trabanelli, Corrosion and corrosion inhibition of alumina particulate/aluminium alloys metal matrix composites in neutral chloride solutions, Journal of Applied Electrochemistry 27(3) (1997), 325-334. https://doi.org/10.1023/A:1018436931465

[17] B. Mullins, Australian Eucalyptus, Sydney: A. H. \& A. W. Reed, 1979. 
[18] M. Abdallah, Basim H. Asghar, I. Zaafarany and A. S. Fouda, The inhibition of carbon steel corrosion in hydrochloric acid solution using some phenolic compounds, International Journal of Electrochemical Science 7 (2012), 282-304.

[19] N. O. Eddy, Inhibitive and adsorption properties of ethanol extract of Colocasia esculenta leaves for the corrosion of mild steel in $\mathrm{H}_{2} \mathrm{SO}_{4}$, International J. Phys. Sci. 4(4) (2009), 165-171.

[20] A.R. Pentold and J. L. Willis, The Eucalyptus, Landon: Leonard Hill, 1961.

[21] M. Ralph, Seeds Collection of Australian Native Plants: For Revegetation, Tree Planting and Direct Seeding, 2nd ed., Bushland Horticulture, Fitroy, VIC, 1994.

[22] Y. L. Saraswathi, S. Das and D. P. Mondal, A comparative study of corrosion behavior of Al/SiCp composite with cast iron, Corrosion 57(7) (2001), 643-653. https://doi.org/10.5006/1.3290391

[23] N. G. Walsh and T. J. Entwisle, Flora of Victoria, Volume 3, Inkata Press, Melbourne, VIC, 1996.

[24] N. Wilson, The Flooded Gum Trees: Land Use and Management of River Red Gums in New South Wales, Sydney: Nature Conversation Council of NSW, 1995.

[25] Zaki Ahmed and B.J Abdul Aleemi, Degradation of aluminum metal matrix conposites in salt water at it control, Materials \& Design 23 (2002), 173-180. https://doi.org/10.1016/S0261-3069(01)00066-8

[26] P. C. Okafor, M. E. Ikpi, I. E. Uwah, E. E. Ebenso, U. J. Ekpe and S. A. Umoren, Inhibitory action of Phyllanthus amarus extracts on the corrosion of mild steel in acidic, Corrosion Science 50 (2008), 2310-2317. https://doi.org/10.1016/j.corsci.2008.05.009

[27] O. K. Abiola and A. O. James, The effects of Aloe vera extract on corrosion and kinetics of corrosion process of zinc in $\mathrm{HCl}$ solution, Corrosion Science 52 (2010), 661-664. https://doi.org/10.1016/j.corsci.2009.10.026 